\title{
Work-related musculoskeletal disorders of the upper extremity with reference to working posture of secretaries
}

\author{
Ashiyat Akodu, Ph.D PT \\ Lecturer, Department of Physiotherapy, College of Medicine, University of Lagos
}

\author{
Adegoke Akinfeleye, MSC PT \\ Senior physiotherapist, Department of Physiotherapy, Lagos University Teaching Hospital
}

Latifat Atanda, BSC PT

Physiotherapist, Department of Physiotherapy, Lagos University Teaching Hospital

Suleiman Giwa, FWACS,

Consultant Orthopaedic Surgeon, Department of Surgery, College of Medicine, University of Lagos

Introduction: This study investigated the prevalence of work related musculoskeletal disorders (WMSDs) of the upper extremity and low back among secretaries in a state public service and their associations with working posture.

Methodology: A cross sectional survey was carried out among 150 secretaries randomly selected within the Lagos State Civil Service Secretariat, Ikeja, Lagos, Nigeria, by using a 52-item questionnaire which captured information on work related musculoskeletal disorders (WMSDs). Working posture was assessed by measuring the variation in craniovertebral angle (CVA) and using Rapid upper limb assessment (RULA) scores of participants.

Results: The prevalence of WMSDs of low back, neck, shoulder and hand of the participants in this study was observed to be $71.3 \%$, $59.3 \%, 48.0 \%$ and $28.0 \%$ respectively. The results of this study showed a significant difference in CVA and the RULA scores ( $p=$ $0.02)$, between participants with neck pain and those without neck pain, hand pain and those without hand pain $(p=0.003)$, low back pain and those without low back pain $(p=0.004)$.

Conclusion: This study shows a high prevalence of upper extremity and low back musculoskeletal disorders among secretaries in Lagos State Civil Service Secretariat, Ikeja, Lagos Nigeria. Neither CVA nor RULA scores were associated with shoulder pain.

Key words: Occupational Health, Cranio vertebral angle, Rapid upper limb assessment, Musculoskeletal discomfort

\section{INTRODUCTION}

Technological advances, mainly, usage of computers, have revolutionalised workstations. Computers have become an integral part of life. However, its use is not free from health hazards. Literature indicates that intensive use of computers result in joint and muscle stress and strain, because of the continuous and repetitive nature of movements'. Literature further suggests that individual factors, prolonged awkward postures, poor workstation design and psycho-social environment can lead to development of symptoms of musculoskeletal discomfort ${ }^{1,2}$.

Awkward posture increases the discomfort and pain experienced in different body parts such as back, neck and shoulders ${ }^{3}$. Musculoskeletal disorders are the most common reason for reported workrelated illness, long term sick leave and disability pensions ${ }^{4}$. The index of prevalence of musculoskeletal disorders associated with work related awkward sitting postures is very high ${ }^{5}$. Physical risk factors (such as prolonged sitting and neck flexion) have been identified as predictive of neck, shoulder, hand and low back musculoskeletal disorders in the study of a mixed population of workers from various industrial, health and professional settings ${ }^{6}$. These and other physical factors (such as posture and neck muscle endurance) have not been prospectively investigated specifically among office workers. Studies by Adedoyin et al. ${ }^{7}$ and Omokhodion and Sanya ${ }^{8}$ reported high prevalence of Workrelated Musculoskeletal Disorders among office computer users in Nigeria but no reports on its association with working posture.
Apart from personal suffering, these conditions impose a major financial burden on the community, on employers and on individuals?.

Upper extremity musculoskeletal disorders (UEMSDs) are disorders affecting soft tissues of the neck, shoulder, arms, and hands ${ }^{10}$. The majority of UEMSDs are characterised by repeated episodes of pain accompanied by disability, varying in severity and impact ${ }^{2}$. Most of the episodes are self-limiting and subside within days or weeks, while some end up with long-term chronic problems ${ }^{2}$. Risk factors from physical, psychological, and social domains have been acknowledged, but the relative influence of the several risk factors on the onset and exacerbation of UEMSDs is not clear. As a result, arguments still exist regarding the degree of work-relatedness of UEMSDs ${ }^{\prime \prime}$.

A survey was done in Nigeria and reported that the prevalence of upper extremity musculoskeletal disorders was found to be Neck $(66.8 \%)$ and shoulder $(60.1 \%)$, followed by hand $(32.6 \%)$, upper $\operatorname{arm}(32.0 \%)$, lower $\operatorname{arm}(31.5 \%)$, wrist $(28.1 \%)$, and elbow $(22.5 \%)$ among computer users in a bank ${ }^{12}$.

Low back pain is a common musculoskeletal disorder affecting $80 \%$ of people at some point in their lifetime ${ }^{13}$. With conventional measures, the symptoms of low back pain typically show improvement within a few weeks from onset ${ }^{14}$.

Maintenance of posture is a result of many underlying processes and tensional relationships throughout the body. As such, posture becomes a measure of the overall balance in the body 
and can be used as a tool to assess if interventions have caused a change in overall body balance ${ }^{15}$. An ideal posture is stable, maintains the body's centre of gravity/mass over its base of support, minimises stress and strain on tissues, both statically at rest and dynamically during movement and minimises energy $\operatorname{cost}^{16}$. In the practice of physiotherapy, posture is a concept frequently used in examining people and determining if treatment, particularly for back and neck problems, has made any changes in a person. Posture is defined as 'the attitude or characteristic manner of bearing one's body' i.e. the relative arrangement of body parts for a specific activity ${ }^{17}$.

The result from a prospective study by Ariens et $a^{18}$ showed a positive association between sitting at work for more than $95 \%$ of working time and neck pain; a trend was also observed for positive relation between neck flexion and neck pain. Non neutral postures of the shoulder (such as flexion and abduction) have been found to be associated with musculoskeletal symptoms ${ }^{19}$. Working with the body in a neutral position reduces stress and strain on muscles, tendons, and skeletal system and reduces the risk of developing a musculoskeletal disorder ${ }^{20}$.

Various postural analysis methods using computer software and methods exist: such as Rapid Upper Limb Assessment worksheet (RULA), Ovako Working Posture Analysis System (OWAS), National Institute for Occupational Safety and Health (NOISH), Method Time Measurement (MTM) together with calculating energy expenditure. These can be used to evaluate working posture and physical workload to avoid work related musculoskeletal disorders ${ }^{21}$. RULA is a tool that assesses biomechanical and postural loading on the whole body with particular attention to the neck, trunk and upper limbs. Measurement of cranio vertebral angle, (CVA) is one of the common methods in assessing head posture ${ }^{22}$.

In addition survey methods developed for use in ergonomic investigations of workplaces where work related upper limb disorders are reported ${ }^{23}$ are also used. Apart from individual suffering; these conditions inflict a major financial burden on the community, on employers and on individuals ${ }^{9}$. Due to high prevalence of musculoskeletal disorders and its association with awkward sitting postures ${ }^{5}$ it was decided that the aim of this study was to investigate the prevalence of work related musculoskeletal disorders of neck, shoulder, hand and low back and their association with working posture among secretaries in Lagos State Civil Service.

\section{METHODOLOGY}

\section{Research design}

A quantitative descriptive design was used.

\section{Materials and methods}

\section{Subject Selection}

A multi stage sampling technique was used in selecting participants for this study. In the first stage, 34 ministries representing two-thirds of all ministries (5I) in the secretariat were selected by a simple random sampling technique using balloting method.

In the second stage, in each of the ministries selected in the first stage, 5 different units were randomly selected by balloting method and the secretaries in each unit were recruited for this study.

A total of I50 secretaries participated in this study. They were recruited from Lagos State Civil Service Secretariat, Alausa, Ikeja Lagos, Nigeria. Included were participants who make use of computers and work for at least 4 hours per day and who had at least I years work experience as well as secretaries who underwent neck and low back surgery.

Excluded from the study were participants whose tasks do not include the use of computer for at least 4 hours per day or who were not computer literate with less than I year work experience. Prior to the commencement of the study participants demographic data such as age, gender, weight and height, were obtained.

\section{Ethical Consideration}

Informed written consent was obtained by providing a consent form for the participants to complete. Ethical approval was sought and obtained from the Health Research and Ethics Committee of Lagos University Teaching Hospital, LUTH, Idi- Araba, Lagos.

Also, approval was sought from the management of the ministries at Alausalkeja. A letter stating the purpose of the study, assuring participants of confidentiality and seeking informed consent was distributed with each copy of the questionnaire.

\section{Procedure for data collection}

Participants were requested to firstly complete a biographic questionnaire, secondly, the craniovertebral angle was obtained, and lastly the RULA was administered.

The biographical questionnaire, titled Work Related Upper Extremity and Low Back Musculoskeletal Disorders Questionnaire ${ }^{24}$, consisted of 52 questions divided into 4 sections. This was used to collect information on personal characteristics, working condition and musculoskeletal pain:

SECTION A: collected information on the personal characteristics of the participants, and this include; age, sex, marital status, educational qualification, grade level, years spent on job, weight, height, body mass index (BMI), cranio vertebral angle (CVA).

SECTION B: collected information on the working conditions.

SECTION C: collected information on the musculoskeletal complaints such pain, discomfort and stiffness of neck, shoulder, hand and low back.

Assessment of craniovertebral angle, was done with a plumb line set I meter away from the participants' work station with the tripod stand and camera set just behind it (Figure I). After this, the participants were asked to expose their ear, the neck to its base and the shoulder. The lateral landmarks were marked at the tragus of the ear, spinous process of the seventh cervical vertebrae and the acromion process of the shoulder with adhesive paper contrasting the skin. The plumb line was expected to fall in front of or through the tragus of the ear and in front of the acromion process. Participants' photographs were taken whilst they were working on their computers without their knowledge at the time. The pictures were imported to Corel draw $\mathrm{X} 5$ evaluation version to measure the cranio vertebral angle.

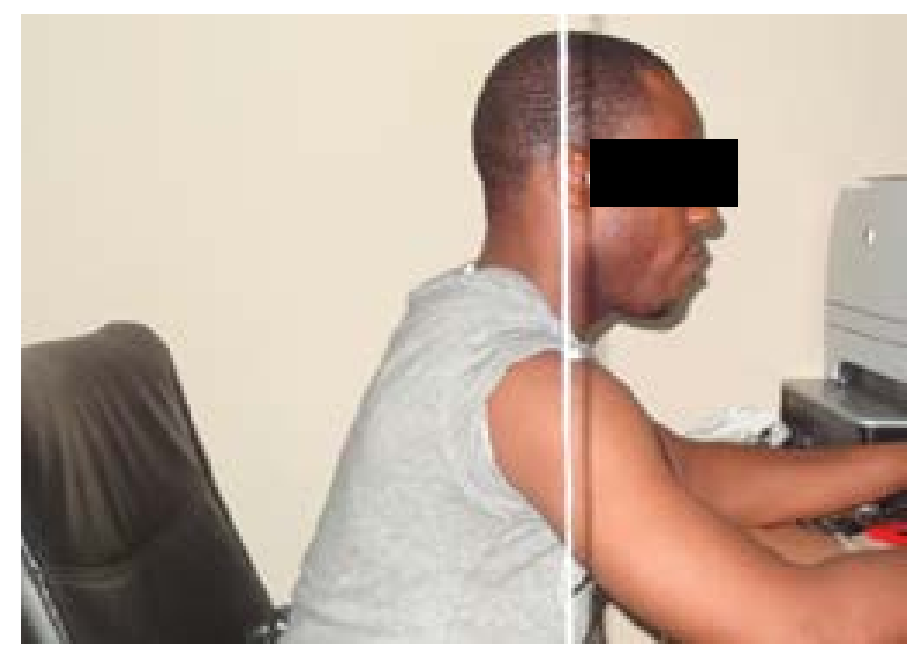

Figure I: Assessment of participant's cranio vertebral angle

To measure the cranio vertebral angle (head protrusion angle) ${ }^{22}$, a horizontal line starting from the spinous process of the $7^{\text {th }}$ cervical vertebrae was drawn using the angular dimension of the Corel draw $\times 5$ evaluation software. Also a diagonal line was drawn through the tragus of the ear to the spinous process of the 7th cervical vertebrae. The cranio vertebral angle (Figure 2 ) formed 
at the point where these two lines met (spinous process of the 7th cervical vertebrae) was measured and recorded. The smaller the angle, the greater the forward head posture (FHP) indicating a greater shift of the head from the sagittal plane (plumb line). The larger the angle the more it is representative of an 'ideal' sagittal plane of the head and neck alignment ${ }^{22}$. Yip et al. ${ }^{22}$ concluded that patients with smaller CVAs had greater FHP and the greater the $\mathrm{FHP}$, the greater the neck disability.

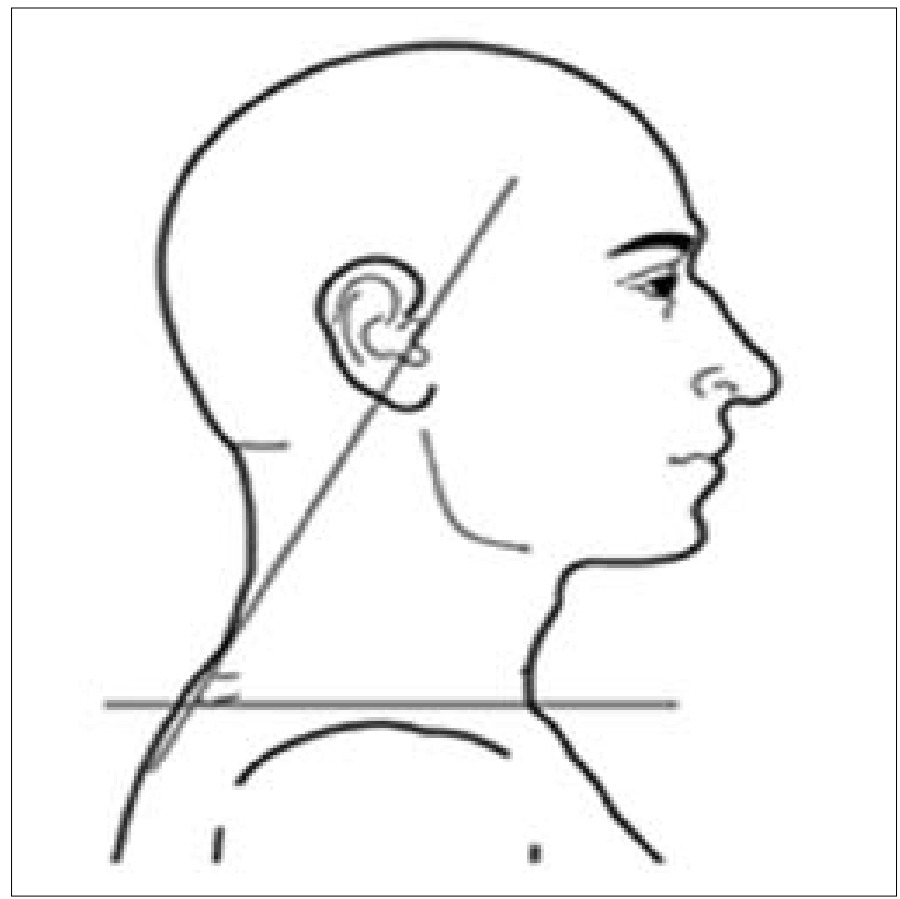

Figure 2: Craniovertebral angle ${ }^{25}$

The RULA employee assessment worksheet ${ }^{26}$ was completed for each participant by the researcher whilst at their computer stations.

RULA is a quick survey method for use in ergonomic investigations of workplaces where musculoskeletal disorders are reported. It is a screening tool that assesses biomechanical and postural loading on the body. It focuses on the neck, trunk and upper limbs, and is ideal for sedentary workers e.g. computer workplaces. It has been validated on groups of computer users and sewing machine operators. It is quick and easy to complete. RULA scores indicate the level of intervention required to reduce musculoskeletal disease risks. It requires no special equipment and provides a quick assessment of the posture of neck, trunk, upper limbs and lower limbs ${ }^{22}$, scores range from I-7. A score of I or 2 indicates an acceptable posture; 3 or 4 indicates that further investigation is needed and changes may be required; 5 or 6 indicates a need for investigation and changes to be made in the near future. A score of 7 indicates immediate investigation and changes ${ }^{23}$.

This employee worksheet consists of 7 sections:

SECTION A: measures the position of the upper arm with score ranging from I-6, SECTION B: measures the position of the lower arm with a maximum score of 3, SECTION C: measures the position of the wrist, with a maximum score of 6, SECTION D: measures the position of the neck, with a maximum score of 6 , SECTION E: This section measures the position of the trunk with a maximum score of 6 , SECTION F: measures the leg score; time spent of the computer at a stretch, with a maximum score ranging from I-2, SECTION $\mathrm{G}$ :This section measures the force/load score and hours spent on the computer per day.

Summations of these scores give the RULA score. To measure the RULA scores, the researcher observed and scored the positions of neck, trunk, upper limbs and lower limbs.

A high score indicates immediate investigation for musculoskeletal disease risk, while a low score indicates acceptable posture.

\section{STATISTICAL ANALYSIS}

Data analysis was performed using the statistical package for social science SPSS version I7. Descriptive statistics of mean, standard deviation, frequency, percentages and bar charts were used to summarise the results. Inferential statistics of paired t-test and Mann-Whitney $U$ test were used to find the relationship between the variables. The level of significance was set at $p<0.05$.

\section{RESULTS}

\section{The Sample}

A total of 150 secretaries participated in this study. One hundred and twenty two $(81.3 \%)$ of the participants were female while 28 (I8.7\%) were male, with ages ranging from 22 to 57 years. The mean values of age, height, weight and body mass index (BMI) were $43.45 \pm 7.6$ years, $1.63 \pm 0.06 \mathrm{~m}, 72.30 \pm 14.1 \mathrm{~kg}, 27.59$ $\pm 5.5 \mathrm{~kg} / \mathrm{m}^{2}$ respectively (see Table $I$ ).

Table I: Demographic characteristics of the participants

\begin{tabular}{|l|l|}
\hline VARIABLES & $\mathbf{X} \pm$ SD \\
\hline Age (years) & $43.45 \pm 7.55$ \\
\hline Weight $(\mathrm{kg})$ & $72.30 \pm 14.07$ \\
\hline Height $(\mathrm{m})$ & $1.63 \pm 0.06$ \\
\hline BMI $\left(\mathrm{kg} / \mathrm{m}^{2}\right)$ & $27.5 \pm 5.54$ \\
\hline $\begin{array}{l}\text { KEY: } \\
\text { X }=\text { Mean; SD = Standard deviation; BMI = Body mass index }\end{array}$ \\
\hline
\end{tabular}

\section{Working history/habits of participants}

The participants had worked between I and 35 years with a mean of $15.33 \pm 9.6$ years; they work an average of $8.19 \pm 1.7$ hours per day and $5.05 \pm 0.3$ days per week.

The Majority, 109 (72.7\%) took a break from work, 8 (7.3\%) took a 10 minute break, $52(47.7 \%)$ took a 20 minute break, 34 (3I.2\%) took a 30 minute break, I 5 (I3.8\%) took an I hour break, while 4 I (27.3\%) did not take any break (Table II on page 19).

\section{Prevalence of Musculoskeletal Disorders}

In the 12 months preceding this study, participants' prevalence of neck, shoulder, hand and low back pain was $59.3 \%, 48.0 \%, 28.0 \%$ and $71.3 \%$ respectively (Figure 3 ).

The point prevalence of neck, shoulder, hand and low back pain was $39.3 \%, 24.0 \%, 14.7 \%$ and $51.3 \%$ respectively (Figure 3 ).

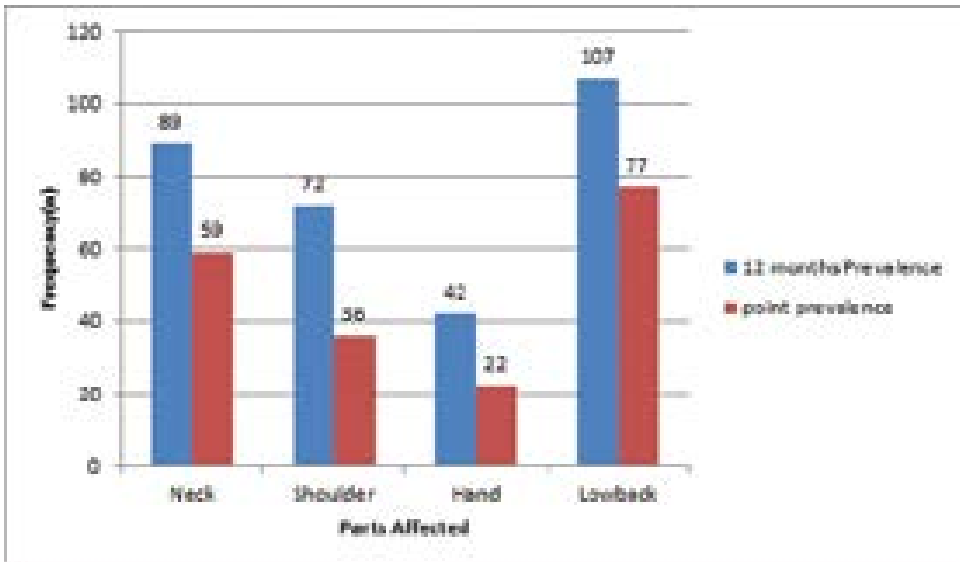

Figure 3: I 2 month's prevalence and point prevalence of neck, shoulder, hand, and low back pain of the participants 
Table II: Working History of the Participants

\begin{tabular}{|c|c|c|}
\hline VARIABLES & $\begin{array}{c}\text { FREQUENCY } \\
\text { (n) }\end{array}$ & $\begin{array}{c}\text { PERCENTAGE } \\
(\%)\end{array}$ \\
\hline \multicolumn{3}{|c|}{ Work experience } \\
\hline$(1-10)$ years & 58 & 38.6 \\
\hline$(\mathrm{I} I-20)$ years & 49 & 32.6 \\
\hline$>20$ years & 43 & 28.8 \\
\hline Total & 150 & 100.0 \\
\hline \multicolumn{3}{|c|}{ Working hours/day } \\
\hline$<8$ hours & 40 & 26.7 \\
\hline 8 hours & 60 & 40.0 \\
\hline$>8$ hours & 50 & 33.3 \\
\hline Total & 150 & 100.0 \\
\hline \multicolumn{3}{|l|}{ Days/Week } \\
\hline 4 days & 3 & 2.0 \\
\hline 5 days & 139 & 92.7 \\
\hline 6 days & 6 & 4.0 \\
\hline 7 days & 2 & 1.3 \\
\hline Total & 150 & 100.0 \\
\hline \multicolumn{3}{|l|}{ Break at work } \\
\hline No & 41 & 27.3 \\
\hline Yes & 109 & 72.7 \\
\hline Total & 150 & 100.0 \\
\hline \multicolumn{3}{|c|}{ Length of break } \\
\hline 10 minutes & 8 & 7.3 \\
\hline 20 minutes & 52 & 47.7 \\
\hline 30 minutes & 34 & 31.2 \\
\hline I hour & 15 & 13.8 \\
\hline Total & 109 & 100.0 \\
\hline
\end{tabular}

\section{Characteristics of Neck, Shoulder and Hand pain}

Sixteen (26.2\%) participants had acute pain in neck, $40(65.6 \%)$ had sub-acute pain and 5 (8.2\%) had chronic pain, $37(60.7 \%)$ participants had pain radiating to the elbow or wrist, while 24 (39.3\%) had localised pain (Table III).

Fifty-five $(76.4 \%)$ had no history of frozen shoulder while 17 (23.6\%) had a history of frozen shoulder (Table III).

Nine (25\%) participants had acute pain, $23(63.9 \%)$ had subacute pain and 4 (I I.I\%) had chronic pain, I 7 (47.2\%) participants reported one spell of shoulder complaints while 19 (52.8\%) had recurrent episodes (Table III).

Eight $(36.4 \%)$ had acute pain in the hand, I I (49\%) had subacute pain and 3 (I3.6\%) had chronic pain (Table III).

\section{Characteristics of low back pain}

The 12 months prevalence of low back complaints among participants in this study was $107(71.3 \%)$ out of which $7(6.5 \%)$ were hospitalised and 2 (1.9\%) changed jobs due to their low back pain. Fifty-seven $(53.3 \%)$ participants had a history of low back pain while, $50(46.7 \%)$ had no history of lumbago.

The point prevalence was 77 (7I.9\%); 26 (33.3\%) had acute pain, $39(50.6 \%)$ had sub-acute pain and 12 (I5.6\%) had chronic pain. 34 (44. I\%) of the participants reported one spell of low back pain while $42(55.9 \%)$ had recurrent episodes.

Participants described the nature of their back complaints: as feeling extremely tired, stiffness, nagging feeling, numbness, tingling, loss of strength, cramp or spasm and pain. 34 (44.2\%) experienced pain only; 32 (4I.6\%) experienced pain and tingling sensation; 8

Table III: Characteristics of pain in various body parts

VARIABLES

FREQUENCY

(n)

(\%)

\section{Characteristics of neck pain}

Severity

\begin{tabular}{|l|c|c|}
\hline Acute & 16 & 26.2 \\
\hline Sub-acute & 40 & 65.6 \\
\hline Chronic & 5 & 8.2 \\
\hline Total & 61 & 100 \\
\hline
\end{tabular}

Pain radiation

\begin{tabular}{|l|c|c|}
\hline Yes & 37 & 60.7 \\
\hline No & 24 & 39.3 \\
\hline Total & 61 & 100 \\
\hline
\end{tabular}

Characteristics of shoulder pain

\begin{tabular}{|c|c|c|}
\hline \multicolumn{3}{|c|}{ Frozen Shoulder } \\
\hline Yes & 17 & 23.6 \\
\hline No & 55 & 76.4 \\
\hline Total & 72 & 100 \\
\hline \multicolumn{3}{|l|}{ Severity } \\
\hline Acute & 9 & 5.0 \\
\hline Sub-acute & 23 & 63.9 \\
\hline Chronic & 4 & II.1 \\
\hline Total & 36 & 100 \\
\hline \multicolumn{3}{|c|}{ Duration of Pain/Recurrence } \\
\hline One spell & 17 & 47.2 \\
\hline Recurrent & 19 & 52.8 \\
\hline Total & 36 & 100 \\
\hline \multicolumn{3}{|c|}{ Characteristics of hand pain } \\
\hline \multicolumn{3}{|l|}{ Severity } \\
\hline Acute & 8 & 36.4 \\
\hline Sub-acute & $\mathrm{II}$ & 50.0 \\
\hline Chronic & 3 & 13.6 \\
\hline Total & 22 & 100 \\
\hline
\end{tabular}

( $10.4 \%)$ experienced pain, tingling sensation and stiffness; $2(2.6 \%)$ experienced pain, tingling sensation, stiffness and spasm; I (I.3\%) experienced all 5 problems.

Thirty (39.0\%) participants had low back pain radiating to the knee or ankle while 47 (6I.0\%) had localised pain; 22 (28.6\%) participants had sudden onset of low back pain; while the majority, 55 (7I.4\%) had gradual onset of the low back pain.

\section{Relationship between Cranio vertebral angle (CVA) neck, shoulder, hand and low back pain}

Participants without neck pain had a higher CVA (see Table IV on page 20). The paired t-test showed a significant difference $(p=$ 0.02 ) between the CVA of participants with neck pain and those without neck pain.

Participants without shoulder pain had a slightly higher CVA than those with shoulder pain (Table IV). However the paired t-test showed that this difference was not significant $(p=0.14)$.

Participants with hand pain and those without hand pain had approximately the same CVA (Table IV). The paired t-test showed that this difference was not significant $(p=0.8 \mathrm{I})$.

Participants without low back pain had slightly higher CVA than those with low back pain (Table IV). The paired t-test showed that 
Table IV: Cranio-vertebral angle (CVA), Neck, Shoulder, Hand and Low back posture assessment

\begin{tabular}{|l|c|c|c|}
\hline CVA & $\begin{array}{c}\text { X } \pm \text { SD } \\
\text { (Degrees) }\end{array}$ & t-value & P-value \\
\hline Neck pain & $45.85 \pm 6.44$ & -3.20 & $0.02^{*}$ \\
\hline YES & $49.95 \pm 8.32$ & & \\
\hline NO & $46.66 \pm 7.02$ & -1.46 & 0.14 \\
\hline Shoulder pain \\
\hline YES & $48.86 \pm 8.08$ & \\
\hline NO & $48.70 \pm 7.25$ & 0.23 & 0.81 \\
\hline Hand pain & $48.28 \pm 7.99$ & \\
\hline YES & $7.91 \pm 7.78$ & -0.67 & 0.50 \\
\hline NO & $48.78 \pm 7.99$ & \\
\hline Low back pain & \\
\hline YES & \begin{tabular}{l}
$\mid$ \\
\hline NO
\end{tabular} \\
\hline * $=$ significant at $p<0.05$ & \\
\hline $\begin{array}{l}\text { KEY } \\
\text { CVA = Cranio vertebral angle } \\
\text { X = Mean } \\
\text { SD = Standard deviation }\end{array}$
\end{tabular}

Table V: Relationship between RULA employee assessment worksheet and neck, shoulder, hand, low back pain

\begin{tabular}{|c|c|c|c|}
\hline RULA & $X \pm S D$ & U-value & P-value \\
\hline \multicolumn{4}{|c|}{ Neck pain } \\
\hline YES & $4.42 \pm 0.91$ & -3.02 & $0.002^{*}$ \\
\hline NO & $3.84 \pm 0.95$ & & \\
\hline \multicolumn{4}{|c|}{ Shoulder pain } \\
\hline YES & $4.28 \pm 0.91$ & -1.89 & 0.06 \\
\hline NO & $4.01 \pm 0.99$ & & \\
\hline \multicolumn{4}{|c|}{ Hand pain } \\
\hline YES & $4.86 \pm 1.04$ & -2.93 & $0.003^{*}$ \\
\hline NO & $3.94 \pm 0.89$ & & \\
\hline \multicolumn{4}{|c|}{ Low back pain } \\
\hline YES & $4.39 \pm 1.00$ & -2.84 & $0.004^{*}$ \\
\hline NO & $3.75 \pm 0.82$ & & \\
\hline \multicolumn{4}{|c|}{$*=$ Significant at $p<0.05$} \\
\hline \multicolumn{4}{|c|}{$\begin{array}{l}\text { KEY } \\
\text { RULA = Rapid Upper Limb Assessment, Employee assessment } \\
\text { worksheet } \\
X=\text { Mean } \\
\text { SD = Standard deviation } \\
U=\text { Mann-Whitney Test }\end{array}$} \\
\hline
\end{tabular}

this difference was not significant difference $(p=0.50)$.

\section{The relationship between RULA scores and pain experienced}

Participants with neck pain had higher RULA scores (see Table $V$ ). The Mann-Whitney $U$ test showed that there was a significant difference $(p=0.002)$ between the RULA scores of participants with neck pain and those without neck pain.

Participants with shoulder pain had a slightly higher RULA score than those without shoulder pain but the difference was not significant $(p=0.00)$.
Participants with hand pain had higher RULA scores There was a significant difference ( $p=0.003)$ between the RULA scores of participants with hand pain and those without hand pain.

Participants with low back pain had higher RULA scores. There was a significant difference $(p=0.004)$ between the RULA scores of participants with low back pain and those without low back pain.

Treatment received and sick leave of participants

At the time of this study; $3(2 \%), 3(2 \%), ~ I ~(0.6 \%), ~ I 3(8.6 \%)$ participants had consulted more than one specialist for their neck, shoulder, hand and low back pain respectively; while I8 (I2.0\%), I I (26.0\%), 6 (4.6\%), 25 (18.6\%) had consulted a physiotherapist for neck, shoulder, hand and low back pain respectively (see Table VI).

Table VI: Treatment and sick leave of participants

\begin{tabular}{|c|c|c|c|c|}
\hline & NECK & SHOULDER & HAND & LOWBACK \\
\hline \multicolumn{5}{|c|}{ Treatment } \\
\hline$A$ & $40(26.6 \%)$ & $22(14.6)$ & 15 (10\%) & $39(26 \%)$ \\
\hline B & $18(12 \%)$ & II (26\%) & $6(4.6 \%)$ & $25(18.6)$ \\
\hline C & $3(2 \%)$ & $3(2 \%)$ & I (0.6\%) & 13 (8.6\%) \\
\hline \multicolumn{5}{|c|}{ Sick leave } \\
\hline Yes & $9(6 \%)$ & $3(2 \%)$ & $2(1.3 \%)$ & II(26\%) \\
\hline No & $52(34.6)$ & $33(22 \%)$ & $20(13.3 \%)$ & $65(43.3 \%)$ \\
\hline \multicolumn{5}{|c|}{$\begin{array}{l}\text { KEY } \\
A=\text { No treatment } \\
B=I \text { specialist, Physiotherapist } \\
C=\text { more than I specialist }\end{array}$} \\
\hline
\end{tabular}

Some had taken a sick leave due to neck, shoulder, hand or low back pain. $9(6 \%)$ took leave due to neck pain, $3(2 \%)$ due to shoulder pain, 2 (I.3\%) due to hand pain and II (26.0\%) due to low back pain.

\section{DISCUSSION}

The purpose of this study was to determine the prevalence of work related musculoskeletal disorders of upper extremity and low back and their association with working posture among secretaries in Lagos State Civil Service, Lagos Nigeria.

The prevalence of WMSDs of low back, neck, shoulder and hand of the participants in this study was found to be $71.3 \%, 59.3 \%$, $48.0 \%$ and $28.0 \%$ respectively, making low back the most frequent area of discomfort among the participants. This result agrees with the result of the study by Adedoyin et al. ${ }^{7}$, who reported the prevalence of WMSDs in the low back, neck, shoulder, wrist and fingers to be $74 \%, 73 \%, 63 \%, 67 \%$ and $65 \%$ respectively among computer users in 6 federal universities in Nigeria. These results also support the study by Shikdar and $\mathrm{Al}-\mathrm{kindi}^{27}$ that reported the major complaint of WMSDs among computer users to include shoulder (45\%), low back (43\%), neck (30\%) and wrist (30\%) complaints. Omokhodion and Sanya ${ }^{8}$ reported $46 \%$ and $38 \%$ as the prevalence of low back pain among office workers in Ibadan, Nigeria.

Findings from this study, reveal that there was a significant difference in CVA between participants with neck pain and those without neck pain corresponding with the study of Yip et al. ${ }^{22}$, who found out that subjects with neck pain had a significantly smaller CVA than asymptomatic subjects. The smaller the angle the greater the protrusion or forward head posture ${ }^{22}$.The smaller the angle, the greater the forward head posture (FHP) indicating a greater shift of the head from the saggital plane (plumb line). The larger the angle the more it represents of an 'ideal' sagittal plane of the head and neck alignment ${ }^{22}$. Yip et al..$^{22}$ concluded that patients with smaller CVAs had greater FHP and the greater the FHP, the greater the neck disability.

The result of the study by Rahmatalla and Deshaw ${ }^{28}$ shows that musculoskeletal discomfort increases with forward head posture. 
This is supported by the results from this study.

It seems that previous studies have only used CVA, also known as the head protrusion angle ${ }^{22}$, to investigate its relationship with neck pain. This study included the effect of CVA on pain of the shoulder, hand and low back.

Results from this study failed to show that the CVA had an effect on reported pain at the shoulder and hand. The same was true for low back pain. CVA therefore may not be a sensitive measure in assessing hand, shoulder or low back pain.

High RULA scores in this study also seem to be able to differentiate between 'good' and 'bad' postures with participants with a higher RULA scores reporting neck pain. Participant with pain had a higher RULA score. This is consistent with findings from a study by Choobinehet al. ${ }^{29}$. They established that a very high RULA score of action level of $3 \& 4$ indicated that further investigation is needed and changes may be required.

The lack of significant difference in RULA scores between participants with shoulder pain and those without shoulder pain agrees with the study of Marcus et $a l^{30}$, which found that non neutral postures of the shoulder were not associated with shoulder pain. Therefore this suggests that RULA may not be a sensitive measure for assessing shoulder posture.

The results of this study showed that participants with musculoskeletal disorders and those without musculoskeletal disorders have a RULA score of 3 or 4 and above. This agrees with the study by Choobinehet al. ${ }^{29}$ that found that a high RULA score of 3 or 4 and above was obtained when the Nordic musculoskeletal questionnaire ${ }^{24}$ and RULA were used to establish the presence of WMSDs. This, according to the RULA guideline implies that posture assumed by participants is poor. This could be as a result of section $G$ of the RULA sheet which measures the hours spent on the computer per day.

The high prevalence of low back pain among the participants may be as a result of awkward posture and prolonged sitting patterns assumed while working on the computer and the kind of chairs used by the participants. Therefore computer workers should be educated on ergonomics, posture, taking a break in between work and relaxation. This will ultimately improve job satisfaction and performance.

Further studies should be carried out to access a posture assessment tool that is specific to shoulder posture.

\section{CONCLUSION}

There was a high prevalence of low back, neck, shoulder and hand musculoskeletal disorders among secretaries in Lagos State Civil Service, Lagos Nigeria. The lower back is the most commonly affected body part among the participants. Poor posture is a high risk factor for the prevalence of neck musculoskeletal disorders among computer users.

\section{REFERENCES}

I. Bhanderi D, Choudhary SK, and Dosh V. A Study of Occurrence of Musculoskeletal Discomfort in Computer Operators. Indian journal of community medicine, 2008; 33 (I): 65-66.

2. Johan HA, Nils F, Jane FT, Sigurd M. Risk factors for neck and upper extremity disorder among computer users the effect of intervention: An overview of systematic review. Plos one, 201 I; 6 (5) el969l. http://dx.doi.org/10.1371\%2Fjournal.pone.0019691.

3. Ghosh T, Das B, and Gangopadhyay S. Work-related Musculoskeletal Disorder: An Occupational Disorder of the Goldsmiths in India. Indian journal of community medicine, 20 I 0; 35 (2): 32 I-325.

4. Kindenberg $U$, Mortimer M and Tornqvist EW. Work-related? Neckshoulder-arm disorders. Report no 2:2006. SALTSA - Joint Programme for Working Life Research in Europe. The National Institute for Working Life and Swedish Trade Unions in Cooperation. 2006.

5. Gerbaudo L, Violante B. Relationship between musculoskeletal disorders and working posture. MedLav, 2008;99 (I): 29-39

6. Ylinen J, Takala EP, Nykanen M, Hakkinen A, Malkia E, Pohjolainen T. Active neck muscle trainingin the treatment of chronic neck pain in women: Rarandomized controlled trial. JAMA, 2003; 289
(19): 2509-16.

7. Adedoyin UO, Idowu BO, Adegunodo RE, Owoyomi AA Idowu PA Musculoskeletal pain associated with the use of computer system in Nigeria. Techno Health Care. 2005; 13 (2): I25-130.

8. Omokhodion FO, Sanya AO: Risk factors for low back pain among office workers in Ibadan, Southwest Nigeria. Occupational Medicine, 2003; 53: 287-289.

9. Craig WM. Musculoskeletal disorders of upper extremity. Are they associated with computer work? Retrieved from http://www. worksafebc.com/health care providers/assets/pdf/musculoskeletal disorders.pdf7// I/I $\overline{4}$. (2007).

10. Jung-Keun $P$ and Seung-Heej.Association between Upper Extremity Musculoskeletal Disorders and Psychosocial Factors at Work: A Review on the Job DCS Model's Perspective. Saf Health Work. 2010; I(I): 37-42.

II. Silverstein MA, Silverstein BA, Franklin GM. Evidence for workrelated musculoskeletal disorders: A scientific counterargument. Journal of Occupational and Environmental Medicine, 1996; 38 (5): 477-484.

12. Tella BA, Akodu AK, Fasuba OO. The prevalence of neck and upper extremity repetitive stress injury among bank workers in Surulere, Lagos, Nigeria. Internet Journal of Rheumatology, 20 I I;6 (2) DOI: $10.5580 / 2900$

13. Bakhtiary AH; Safavi-Farokhi Z; RezasoltaniA. Lumbar stabilizing exercises improve activities of daily living in patients with lumbar disc herniation. Journal of Back and musculoskeletal Rehabilitation, 2005; 18:55-60.

14. Koes BW, van Tulder MW, Lin CWC, Macedo LG, McAuley J, Maher $\mathrm{C}$ : An updatedoverview of clinical guidelines for the management of non-specific low back pain in primary care. Eur Spine J, 20 I0; 19: 2075-2094.

15. Macy J. Physical therapy and posture.2004. Available @ www. posture.com. Accessed on 09/06/14.

16. Thompson D. Biomechanics of standing posture. 200I. Available @ http://moon.ouhsc.edu/dthompsp/namics/coupled.htm. Accessed on $12 / 11 / 14$

17. Smith LK, Weiss EL, Don Lehmkuhl L. Posture, Brounstum clinical kinesiology, $5^{\text {th }}$ edition. Philadelphia FA 1996; Chapter 12: 40 I-4I0.

18. Ariens GA, Bongers PM, Douwes M. Are back flexion, neck rotation, and sitting at work risk factors for neck pain? Results of a prospective cohort study. Occupational and Environmental Medicine, 200 I; 58: 200-207.

19. Tiltiranonda P, Barrastero S, Rempel D. Risk factors for Musculoskeletal disorders among Computer users. Occupational Medicine, 1999; 14: 17-38

20. OSHA: European Agency for Safety and Health at Work. 2015. Available@ http://osha.europa.eu

21. Agrawal DN, Madankar TA, Jibhakate MS. Study and validation of body postures of workers working in small scale industry through RULA. International journal of Engineering science and technology 20I I; 3 (I0): 7732-7734.

22. Yip $\mathrm{CH}$, Chiu TT, Poon AT. The relationship between head posture and severity and disability of patients with neck pain. Manual Therapy, 2008; 13 (2): I48-54.

23. McAtmneyL,\&Corlett EN. RULA: a survey method for the investigation of work-related upper limb disorders. Applied Ergonomics, 1993; (24): 91-99.

24. 24.Kuorinka I, Jonsson B, Kilbom A et al.Standardized Nordic questionnaires for the analysis of musculoskeletal symp-toms. Applied Ergonomics, 1987; 18: 233-237.

25. Fernandez-de-las-penas C, Alonso-Blanco C, Cuadrado ML, Pareja JA. Forward Head Posture and Neck Mobility in Chronic TensionType Headache: A Blinded, Controlled study. Cephalalgia, 2006; 26 (3): 3|4-9.

26. Leuder R. A proposed RULA for computer user: Proceedings of the ergonomic summer workshop, UC Berkeley centre for occupational and environmental health continuing education program. San Francisco. 1996

27. Shikdar AA, Al-Kindi MA. Office ergonomics: deficiencies in computer workstation design. International Journal of Occupational safety Ergonomics, 2007; 13 (2): 215-223.

28. Rahmatalla S, Deshaw, J. Predictive discomfort of non-neutral head-neck postures in fore-aft whole-body vibration. Ergonomics, 
20I I; 54: 263-272, doil0.1080/00I40I39.20I0.547606.

29. ChoobinehAR, Tabatabaei SMR, Tozihian A. Musculoskeletal problems among workers of an Iranian communication company. Indian| Occup Environ Medicine, 2007; I I (I) 32-36.

30. Marcus M, Gerr F, Monteilh C. A prospective study of computer users II: Postural risk factors for musculoskeletal symptoms and disorders. Industrial Medicine, 2002; 4I: 236-249.

\section{Corresponding Author}

AK Akodu

akoduashiyat@gmail.com

Department of physiotherapy

College of Medicine

University of Lagos

Nigeria

PMB I 2003 Idi-araba 